\title{
Path Analysis and Future Prospect of Community Reorganization During Epidemic Period
}

\author{
Chen Wang*, Yanli Li
}

Wuhan University of Technology, Wuhan, China

*Corresponding author. Email: 1091825587@qq.com

\begin{abstract}
With the increasingly obvious tendency of social atomization, whether the community can replace the unit system and realize the effective integration and reorganization of urban grassroots society has been questioned. During the epidemic period, as the key defense line of joint prevention and control and mass prevention and control, the community's "strong intermediary" status was highlighted, the governance grid was consolidated, and new governance forces and resources constantly emerged, showing a trend of further reorganization. The realization of this process depends on the community's centralized collection, development and utilization of information. Therefore, the information network system based on community ecology, science and technology support, openness and people-oriented may become a new driving force for the future community to build a pattern of collaboration and broad participation, with the goal of benefiting all.
\end{abstract}

Keywords: COVID-19, Community Governance, Reorganization.

\section{疫情期间社区再组织化的路径分析与未来展望}

\author{
王琛*, 李艳丽
}

武汉理工大学, 武汉, 中国

*通讯作者. 邮箱: 1091825587@qq.com

\section{中文摘要}

随着社会原子化倾向日益明显，社区能否接替单位制实现城市基层社会的有效整合与再组织化受到质疑。疫情 期间，作为联防联控、群防群控的关键防线，社区“强中介”地位凸显，治理网格得到巩固，新治理力量与资源 不断涌现, 呈现出进一步再组织化趋势。而这一过程的实现有赖于社区对信息的集中收集、开发与利用。由此, 基于社区生态、科技支撑、具有开放性、以人为本的信息网系统或可成为未来社区打造共建共治共享治理格局 的新推动力。

关键词: 新冠疫情, 社区治理, 再组织化

\section{1. 问题的提出}

2019 年末，新冠疫情在湖北省武汉市暴发。广大 社区作为联防联控、群防群控的关键防线, 在抗疫过 程中积极探索创新, 不仅有效遏制了病毒的大范围扩 散, 也为基层常态化治理带来了新发展。
在本次疫情防控中，大数据分析表现十分“亮眼”。 张宇栋等人就社区个人数据应用与隐私保护的矛盾 问题进行了深入探讨 [1]。何雪松、李佳薇通过反思社 区防控暴露出的信息症结, 提出了数据化时代社区信 息治理体系的重构方案[2]; 为应对疫情冲击, 社区网 
格迅速强化升级, 发挥了重大作用。容志看到了这一 “整体网格”的组织能力, 认为通过一体化网格建构基 于生活空间的共同体有可能成为新时代基层社会再 组织化的实现路径之一[3]。刘春呈则重点分析了社区 网格在防控工作中的功能再造及管理短板, 提出以社 区防疫为契机推动网格化管理的系统性优化[4]。目 前, 新冠疫情的影响还未完全消除, 相关研究依然在 不断积累之中, 已有研究大多从负面角度出发, 聚焦 社区在疫情防控期间暴露出的问题与不足, 以期能对 症下药，提升社区治理水平，却往往忽略了疫情期间 社区展现出的积极一面, 总体上对社区抗疫过程中取 得的治理成果分析与治理经验总结不足。本文将着眼 于疫情期间社区同舟共济的抗疫经历, 探索社区在这 一过程中实现高度再组织化的路径与关键, 希望能为 后疫情时代社区常态化治理提供有益参考。

\section{2. 基层再组织化与社区治理}

“再组织化”是“组织化”的衍生概念。社会组织化是 一个通过整合不同群体以更好地实现管理与服务的 过程。任何社会都是组织的社会, 当经历重大变革时, 原有的社会组织形式因与新环境不相适应而走向崩 溃, 此时松散的社会便需要被重新再组织起来进行发 展建设。冊庸置疑, 处于转型时期的中国必然要经历 社会再组织化过程。

单位制曾被认作是新中国成立以来最佳的社会整 合方式, 它的推广与应用为当时集中力量优先发展重 工业, 加快推进社会主义建设, 稳定社会秩序, 巩固 新生政权提供了有力支持。单位制的高度组织化能力 主要体现在三个方面: 一是个人对单位的完全依附。 职工的政治、经济、生活诉求都要通过单位来满足, “单位人”身份是许多个人活动（如婚姻登记、户口登 记、工作调动等) 合法性的来源; 二是高覆盖性的组 织化结构, 单位制不仅将职工, 而且将职工家属都吸 纳到单位体系之中进行管理和控制, 随着“三大改造” 和“大跃进”运动的深入开展, 城市居民基本上都实现 了单位就业; 三是对资源的全面占有, 也正是国家控 制着绝大部分资源, 代表国家处置分配资源的单位才 获得社会成员的高度依赖，实现对社会的高度整合。

20 世纪 70 年代末, 一场深刻的去组织化变革在全 国各地开展。经济所有制结构出现松动, 越来越多的 资源向体制外流动，越来越多的“单位人”变为“社会 人”, 单位所塑造的组织化空间被打破。为接替单位 制的社会整合功能, 实现基层社会的再组织化, 政府 于 20 世纪末大力推动社区建设在全国落地。

基层是社会的缩影，从单位制到社区制，城市基 层管理制度的变迁真实反映了中国社会“组织化一去 组织化一再组织化”的发展历程。但在实践层面, 目 前社区参与不足、自我组织失效、个体原子化发展倾 向加剧等问题显著, 通过基层自治实现社会再整合的 想法受到挑战, 在市场经济条件下社会再组织化的实 现程度遭到质疑。
2020 年初, 作为新冠疫情重灾区, 武汉施行了严 厉的封城举措。在封闭管理期间, 各项经济社会活动 基本停摆, 民众居家隔离, 日常生活高度依赖社区, 这情状让人不禁联想到“单位制”时期的基层管理状 态。为抗击疫情, 社区一系列的应急反应虽然“畸形”, 但联防联控、群防群控的战略部署促使社区在一定程 度上呈现出了进一步再组织化趋势。在地位上, 社区 的重要性得到重新发现; 在结构上, 社区治理网格更 加巩固; 在资源上, 越来越多的治理力量与资源向社 区汇集，展现了社会主义市场经济条件下城市基层社 会整合的巨大潜力, 为社区实现更大范围上的再组织 化提供了一种可能。

\section{3. 疫情期间社区再组织化的路径}

\section{1. 社区“强中介”地位凸显}

社区的概念早在上世纪 30 年代初就被引入中国, 经历过几十年的沉寂, 在改革开放的历史新时期被再 次提起。在全能政府逐步退出、个人对国家强依附性 出现松动、社会面临原子化危机的背景下, 社区建设 对将自主但分散的社会成员再组织起来的意义重大。 田毅鹏在研究中将社会原子化定义为“在社会重大转 型变迁时期, 由于人类社会最重要的社会联结机制

一中间组织的解体或失缺而产生的个体孤独、无序 互动状态和道德解组、人际疏离、社会失范的社会总 体性危机”[5], 因而超越社会原子化危机的关键在于 “重构一个有活力的中间组织体系”[6], 使个体能通过 群体的力量更好地自下而上表达诉求, 能以群体的形 式更好地接受有效的自上而下组织化管理。

改革开放之前, 我国对城市基层社会的管理主要 以单位制为主, 街居制为辅。在计划经济体制下, 所 有的社会资源都把握在政府手中，国家通过单位分配 社会资源来实现对城市基层社会的管理。在当时, 单 位不仅是一种经济组织, 还承担了一系列政治和社会 职能, 涉及城市居民生产生活的方方面面, 从而实现 民众对其工作单位的全面依附一一在经济和社会上 依附于企业, 在政治上依附于工作单位的党政领导, 在个人关系上依附于直接领导 [7]。单位在这一时期充 当了国家与个人之间的唯一中介，“国家一单位一个 人”的纵向组织体系密不透风, 社会组织化整合程度 空前。

随着我国所有制结构的改变, 国家放弃了对部分 社会资源的独占和支配，单位制土崩瓦解，社会流动 因为束缚的减少而越来越自由频繁，城市基层社会重 新回到分散状态，社区承接了单位剥离出来的社会管 理职能。但现阶段的社区无论是在结构上还是在功能 上，很难完全取代单位制达到对基层社会高水准的控 制，“国家一社区一个人”是一种“可选择的非依赖性 关系”, 国家和个人之间由“强中介”转变成了“弱中介” 或“虚中介”状态 $[8]$ 。

2020 年，来势汹汹的新冠疫情肆虐全球，自由自 主的人口流动为病毒提供了传播蔓延的温床。武汉作 
为始发地，被这一全新病毒打了个措手不及。中央政 府当机立断，下达封城指令。疫情暴发初期，大批发 热市民在恐慌心理的影响下，短时间内涌入武汉市各 家定点医院进行治疗, 不仅让疫情下本就紧张的医疗 资源面临进一步的压力，而且在未确诊之前，普通流 感患者和新冠病毒携带者一同就医，更是加剧了交叉 感染的风险。为解决这一问题, 1 月 24 日, 武汉市新 型肺炎防控指挥部发布第 7 号通告, 对新冠肺炎实行 分级诊疗。由全市各社区负责, 全面排查所服务辖区 发热病人（含已就医和未就医市民），并送社区医疗 中心对病情进行篎选、分类。分级诊疗的提出, 将病 人篎选分类的关口前移, 短期内优先保障确诊病人的 医疗需求, 实现有限资源的高效利用。此举不仅分担 了医院的压力, 挽救了濒临崩溃的医疗系统, 更是在 遏制大规模交叉感染事件的发生方面发挥了举足轻 重的作用。至此, 武汉市各大社区站了出来, 成为抗 击疫情的前沿阵地。

2 月 11 日凌晨, 武汉市新冠肺炎疫情防控指挥部 发布第 12 号通告, 即日起在全市范围内所有住宅小 区实行封闭管理。以武汉市 $\mathrm{Q}$ 社区为例, 囊括机关下 沉干部、志愿者、自管党员、社会组织等各类力量的 86 人群众工作队，在 2823 户 6800 人余的社区，包揽 了社区封控、巡逻劝导、出入口 24 小时值守、居民 生活物资保供配送、病患就医等各项工作。社区书记 说:“面对突如其来的疫情和无处不在的感染风险, 作 为一名普通的社区工作者, 也曾害怕过、无助过, 但 是我们身后是 6000 多位居民, 社区就是他们的主心 骨, 我们一步都不能后退。”

疫情期间, 人人居家隔离, 社区的重要性得到重 新发现, 作为国家与个人之间的“强中介”地位凸显, 某种意义上甚至超越了单位制时期对基层社会的把 控。不论平时有多么远离社区公共事务的成员, 在此 时都不得不与社区捆绑在一起，共克时艰。

\section{2. 社区治理网格得到巩固}

从“国家一社会”的视角来看, 实现有效整合, 一 个强有力的中介足以独当一面。但今时不同往日, 缺 少了计划性资源配置的前提, 个体与中介之间的问题 逐渐成为矛盾的主要方面。改革开放之前, 集政治、 经济与社会功能于一体的单位制, 将个人控制在一个 严密的体系之中，“国家一单位一个人”的“控制一依 赖”型垂直社会整合逻辑稳固而畅通。但在社区里, 国家由上到下对居民的动员是通过社区间接传达的， 即国家权力在向下渗透时, 被分为“国家一社区” 以及 “社区一个人”两个环节。后一环节里, 居民与社区保 持强关系的动机减弱, 使社区制下的治理网络较单位 制时期略显松散残损。相对应地，完善城市管理体制 的各类办法和创新性尝试也一直在探索之中。其中, 网格化管理方法在全国各地的实践中不断成熟, 形成 稳定模式。党的十八届三中全会后, 实现“社会管理” 向“社会治理”的转变成为共识。在这一背景下, “网 格化管理”也正积极向“网格化治理”升级。从“管理”
到“治理”，强调了“网格化”服务功能的新内涵，体现 了“以人为中心”的多元参与、协商共治的基层善治愿 景与发展方向。

然而, 在实际推广中, 网格化模式还是暴露出其 科层制基因带来的弊端。网格员由政府部门招聘上 岗, 因而在设置上其实是对行政层级的又一向下延 伸。科层化管理的层级增加, 同时意味着操作成本与 难度的加大, 这种“一笔子插到底”的想法对社区工作 者形成了一种新的压力机制 [9]。社区工作人员平时承 担了过多对上的行政任务, 往往未能真正沉入居民, 了解居民, 导致由网格到居民这“最后一公里”始终难 以打通, 某种程度上背离了“以人为本”的治理理念。 更为准确地说, 社区的工作重点往往放到弱势群体身 上，有相当一部分居民很少同社区打交道，在这一环 节的“社区缺场”极大地影响了居民对社区的认同以 及参与治理的意愿。

抗疫期间，一方面“不落一户，不漏一人”的地毯 式排查要求, 强制社区工作人员真正沉到每家每户了 解情况; 另一方面, 居民在封闭的情况下, 其生活日 常需求、特殊需求也会主动向工作人员曝露。这一来 二去的接触, 是社区工作人员重新向居民亮身份的过 程, 也是社区网格员对分管区域的居民从不知到知、 从知不多到知较多加深了解的过程。社区封控管理这 一特殊情况所引发的联系对网格到居民间的真空有 弥合作用, 进一步拉近了居民同社区的距离, 有利于 从“治理”意义上巩固现有的社区网格。

社区工作人员表示，原先社区主要负责行政和服 务工作, 疫情期间对上的行政工作停止了, 每天在网 格与居民打成一片, 双方加强了沟通, 加深了理解, 情感上也更亲近了; 在服务方面, 社区居民融为一体, 还原了自治本质。疫情过后, 大家对社区的认同感与 归属感更强了, 更多年轻的新鲜血液加入到社区志愿 队伍中来。

\section{3. 更多治理力量与资源涌现}

党的十九大报告提出, 要打造共建共治共享的社 会治理格局, 加强社区治理体系建设, 推动社会治理 重心向基层下移，发挥社会组织作用，实现政府治理 和社会调节、居民自治的良性互动。为推进社区治理 体系与治理能力现代化, 城市基层治理也进行了不少 实践创新, 从“三社联动” (社区、社工、社会组织) 到“五社联动” (社区、社工、社会组织、社会资源、 社区自治组织）, 越来越多的力量团结到社区, 越来 越多的资源汇集到社区。

资源对基层治理具有关键性作用。在计划经济时 期, 所有的资源都在全能型政府的调控下聚集在单位 体制之中, 国家与社会高度一体。单位制崩溃后, 其 所掌握的资源也开始向外流失, 国家从很多场域撤 退。现如今社区负担了包括管理、服务、保障、教育、 安全维稳等各项工作, 单靠社区内部资源难以为继, 其治理外部资源又分散在政府、市场、社会三个不同 
的部门。如何将社会资源再次整合起来实现社区共 建, 是新时期社区治理面临的主要问题之一。

疫情期间, 社区防线的关键性不言而喻, 但基层 防控难度之高、工作量之大与社区防控力量资源有限 的矛盾随之而来。2 月 10 日, 习近平在北京市调研指 导新型冠状病毒肺炎疫情防控工作时强调, “全国都 要充分发挥社区在疫情防控中的阻击作用, 把防控力 量向社区下沉, 加强社区各项防控措施的落实, 使所 有社区成为疫情防控的坚强堡垒”, 奠定了疫情期间 “群防群控”的总体基调。2 月 16 日，《湖北省人民政 府关于进一步强化新冠肺炎疫情防控的通告》中提出 “党政机关、事业单位党员必须就近下沉到村组、社 区参与疫情防控工作, 接受乡镇 (街道) 的管理和调 度”。抗疫期间, 以党建为引领, 以街道社区为作战 单元, 统筹区域内机关企事业单位和商超、酒店、出 租车等行业企业力量, 形成了战“疫”合力。

事实上, 党员干部下沉社区带来的影响远超暂时 补充基层疫情防控人手这一层面。实际调查结果显 示, 疫情过后社区总体上可链接的治理资源更多更丰 富了。以前社区资源大多集中在所在辖区的单位, 疫 情过后, 很多下沉干部和志愿者由于同社区的联系增 加, 渐渐成了社区与其工作单位的资源对接节点。不 同于单位制时期埽涉同一行业部门的单一业缘关系, 得益于现代社区的异质性特点, 来自不同行业领域的 人员下沉极大丰富了聚集在社区资源的多样性。

社会关系网络是链接资源的重要途径之一。格兰 诺维特以“认识时间”“互动的频率”“亲密程度”和“互 惠性服务内容”为标准, 将社会关系划分为强关系和 弱关系, 即两个行为者之间的认识时间较长、互动频 率较高、关系较亲密、互惠内容较广为强关系, 反之 为弱关系[10]。不难看出, 在单位体制下, 城市基层 治理的整合方式是建立在以业缘为主导的强关系基 础上, 是一种比较持久的整合方式。根据格兰诺维特 的研究, 虽然在强关系圈中, 信息重叠程度高, 资源 有效交换率低。但考虑到单位体制下政社一体的现实 状况, 只要强关系圈足够大, 就可以弥补理论上资源 交换缺乏有效性的不足。有学者认为, 在中国强关系 更具有优势，例如费孝通提出的“差序格局” 以及边燕 杰提出的“强关系优势”假设, 但是从另一角度看, 当 今社会异质化程度较高, 强关系圈的范围往往较小, 弱关系网络往往跨越的社会距离较大, 扩展性较好, 嵌在其中的资源自然更为丰富多样。

疫情防控进入常态化阶段后, 武汉市把疫情防控 期间机关企事业单位党员干部下沉社区的经验做法 固化为制度, 推动在职党员干部下沉社区常态化、长 效化, 做到平时服务、战时应急。近些年, 主流人群 “社区缺场”现象引发学界关注, 即体制内人群往往把 社区作为“睡城”, 很少有社区参与行为, 与社区关联 度很弱[11]。这一现象意味着体制内力量在社区治理 场域还有很多挖掘空间。“双报到”制度常态化后, 下 沉党员以工时任务为导向沉到社区, 为社区提供了链
接到各行各业潜在治理资源和力量的“桥”，届时将带 动社会范围内的治理资源源源不断地涌向社区, 社会 治理重心向基层下移目标的实现得以可能。

\section{4. 让社区能的关键}

如果说以往单位之所以能, 凭借的是它对社会资 源的绝对掌控, 那么本文认为, 对信息的掌握以及开 发与利用是如今让社区能的关键。纵观社区再组织化 的实现路径, 战“疫”期间社区能站出来充当个人与国 家之间强中介的底气来源于对辖区范围内居民健康 状况信息的掌握，后来在小区封闭管理阶段，社区充 当了个人与市场之间的中介, 也是出于对个人购买信 息的获取; 其次，得益于社区和居民在疫情期间沟通 与交流的加深, 社区治理网格在此期间不仅得到巩固 与修补，还由于更多有关居民个性化信息的输入得到 升级, 有利于日后社区服务工作更加精准地开展; 最 后, 由弱关系带来的异质性信息接入社区, 让社区拥 有了在更大范围内链接资源的可能。因而, 构建一个 基于社区生态、科技支撑、具有开放性、以人为本的 信息网系统或许就是未来社区构建共建共治共享共 同体的一个关键。

基于社区生态的信息发掘是基础。信息网系统得 以建立的根本在于信息, 其发挥作用的水平也取决于 信息。社区信息网的编织既要体现全面充分, 又要兼 顾一般个别。信息网系统对现实社区生态的描摹越精 细, 其处理结果就越精准, 社区的各项治理行动就越 有据可依。疫情期间社区工作人员为收集居民信息 “跑断腿”“磨破嘴”等现象反映出目前社区在搭建社区 信息网方面仍是任重道远。其背后所隐匿的信息化意 识培养问题、个人隐私与数据使用的矛盾问题等还需 进一步探索解决。

科技支撑是保障。对比十多年前的非典, 今时的 人口流动频率、速度与范围与彼时早已不可同日而 语, 为病毒控制带来了巨大挑战。幸而科技的脚步从 未停止, 大数据分析等方法的运用为新冠疫情防控工 作提供了有力支撑, 在疫情追踪溯源、路径传播分析、 发展模型预测、资源调配等方面做出了突出贡献。随 着社区规模的扩大、居民需求多样化和个性化发展趋 势增强, 单纯的人力必然无法承接只会越来越庞大的 数据分析任务, 因而, 利用信息技术提高数据处理效 率、赋能数据助力社区治理是社区在时代变迁中的必 然选择。

保持开放性是活力源泉。一方面社区内部信息应 保持常更常新, 另一方面要充分重视与开发社区内部 与社区外界相连的信息桥, 在更广阔的平台上进行社 区信息网系统之间的交流与对接。近些年信息不对 称、信息孤岛等问题频繁引发关注，信息不能实现即 时对等的共享确实直接击中了信息网系统长远利用 与建设的七寸。信息实现价值的途径就是传递，封闭 的信息网系统就是停止流动的一潭死水, 终会丧失运 转的活力与动力。 
以人为本是价值导向。人的因素是社区治理的一 切出发点与落脚点, 更是社区信息网系统建设应用的 旨归。利用信息助力社区治理的实践闭环要求服务居 民，更需要依靠居民。对居民信息的发掘来自居民的 赋权，信息网系统的更新与对外联系离不开居民的配 合, 治理的效果评价与改进需要居民的反馈, 施益于 居民的好措施能增强居民对社区的认同，进而会对社 区进一步进行信息赋权。通过与居民之间的良性互 动, 营造有品质、有温度的社区共同体生活才是社区 治理的最终目的。

\section{5. 结语}

组织是人类归属感、安全感的来源。经此一“疫”, 我们看到了社区经历再组织后的强大力量。值得说明 的是，将疫情期间社区的特殊管控状态同单位制时期 相类比, 并不是要再次复刻往日的单位制于今日的中 国，而是想探讨在现今的条件下，社区制如何在地位、 结构、资源方面开辟出一条实现再组织化的新路。单 位制早已远去，是存在着被随时触发可能性的记忆。 社会环境在不到短短半个世纪的时间里发生的变革 之深刻, 让任何试图开历史倒车的想法都没有植根的 现实土壤。

封控下的社区让我们联想到过去, 更通往未来。 疫情期间社区的高度再组织化是“战时状态”下国家 介入的催化结果, 它为在当代中国如何进行社区再组 织和实现怎样的社区再组织效果提供了一种方向与 可能, 即便它的持久性以及是否代表社区再组织能达 到的终极状态都值得怀疑, 但挖掘与研究这段经历, 对有效巩固社区借疫情契机发展而得的治理成果和 社会资本，进一步推动社区共同体建设意义深远。

\section{致谢}

2020 年国家级大学生创新创业训练计划 S202010497141 项目资助

\section{REFERENCES}

[1] Zhang Yudong, Wang Qi, Liu Yi. Application of personal data in community governance in "post epidemic era": Problems and strategies [J]. E-Government, 2021 (02): 84-96.

[2] He Xuesong, $\mathrm{Li}$ Jiawei. Reconstruction of community information governance system in the age of data transformation: reflection on community prevention and control based on new crown pneumonia epidemic [J]. Journal of Hubei University(Philosophy and Social Science), 2020,47 (03): 14-20+172.

[3] Rong Zhi, Qin Hao. Reorganization and modernization of social governance: the operation logic and enlightenment of community "overall grid" in major public health events [J]. The Journal of Shanghai Administration Institute, 2020,21 (06): 66-77.

[4] Liu Chuncheng. Research on community grid management in the context of prevention and control of public health emergencies [J]. Journal of Jiangnan University (Humanities and Social Sciences), 2020,19 (02): 5-13.

[5] Tian Yipeng. Pain of urban social management in China during the transition period: from the perspective of social atomization [J]. Exploration and Free Views, 2012 (12): 65-69.

[6] Tian Yipeng, Lv Fang. Social atomization: theoretical genealogy and its problem expression [J]. Tianjin Social Sciences, 2010 (05): 68-73.

[7] Li Lulu, Wang xiuxiao, Miao Dalei. The perspective and analysis of "New Traditionalism" and its later "Unit System" [J]. Jilin University Journal Social Sciences Edition, 2009,49 (06): 5-16+155.

[8] Ma Weihong, Gui Yong. From control to governance-social transformation and changes of urban grassroots organizational framework [J]. Journal of Huazhong University of Science and Technology(Social Science Edition), 2008 (05): 78-84.

[9] Wang Xuezhu. Grass roots social governance: from grid management to network governance [J]. Theoretical Exploration, 2020 (02): 76-80.

[10] Mark Granovetter, translated by Luo Jiade, Embeddedness-Social Network and Economic Action $[\mathrm{M}]$. Beijing: Social Sciences Academic Press, 2007:69.

[11] Tian Yipeng. Construction of urban community antiepidemic system in the perspective of governance [J]. Social Science Journal, 2020 (01): $19-27+2$ 